\title{
Computerized Neurocognitive Scanning: II. The Profile of Schizophrenia
}

\author{
Ruben C. Gur, Ph.D., J. Daniel Ragland, Ph.D., Paul J. Moberg, Ph.D., Warren B. Bilker, Ph.D., \\ Christian Kohler, M.D., Steven J. Siegel, M.D., Ph.D., and Raquel E. Gur, M.D., Ph.D.
}

Cognitive dysfunction in schizophrenia is well established with neuropsychological batteries, which have assessed multiple domains indicating diffuse deficits especially in processing related to frontotemporal systems. Two studies are reported examining the feasibility of the computerized neurocognitive scan to assess differential deficits in schizophrenia. In Study 1, we tested 53 patients and 71 controls with the traditional and computerized assessments counterbalanced in order. Both showed comparable generalized impairment in schizophrenia with differential deficits in executive functions and memory. The profile was replicated in Study 2 in a new sample of 68 patients and 37 controls, receiving only the computerized scan. The combined sample showed robust correlations between performance on both speed and accuracy measures of the neurocognitive scan and clinical variables, including premorbid adjustment, onset age, illness duration, quality of life, and severity of negative symptoms. These correlations were higher and more prevalent in women than men, who showed correlations predominantly for speed rather than accuracy. Neuroleptic exposure was associated with poorer performance only for speed of memory processing, and in men, this association was seen only for typical neuroleptics. We conclude that the computerized neurocognitive scan can be applied reliably in people with schizophrenia, yielding data that support its construct and criterion validity.

[Neuropsychopharmacology 25:777-788, 2001] (C) 2001 American College of Neuropsychopharmacology. Published by Elsevier Science Inc.
KEY WORDS: Schizophrenia; Neurocognition; Neuropsychological testing; Computerized assessment; Sex differences

Generalized cognitive deficits, considered a critical feature of schizophrenia, have been well documented (Blanchard and Neale 1994; Goldstein 1986; Gur et al.

From the Schizophrenia Research Center, Neuropsychiatry Section, Department of Psychiatry (RCG, JDR, PJM, CK, SJS, REG, WBB), and the Department of Biostatistics and Epidemiology (WBB), The University of Pennsylvania, Philadelphia, Pennsylvania.

Address correspondence to: Ruben C. Gur, Ph.D., Brain Behavior Laboratory, Department of Psychiatry, The University of Pennsylvania, 10 Gates Bldg., 3400 Spruce St., Philadelphia, PA, 19104. Tel.: +1-

215-662-2915; Fax: +1-215-662-7093. E-mail: gur@bbl.med.upenn.edu

Received January 11, 2000; revised April 17, 2001; accepted April 19, 2001.

Online publication: 4/26/01 at www.acnp.org/citations/Npp 042601113.
1997; Heaton et al. 1994). Earlier studies, which commonly focused on one domain such as attention or memory, have not linked cognitive aberrations to brain systems (Calev et al. 1983). However, advances in neuroscience have provided the methodological tools needed to examine schizophrenia from a neuropsychiatric perspective.

The availability of standardized neuropsychological batteries, developed and applied in neurological populations, afforded evaluation of the profile of patients with schizophrenia interpretable from the perspective of regional brain function. Although different tests were applied, they generally tapped the same neurocognitive domains: abstraction and mental flexibility, attention, memory, and language. Against a diffuse pattern of dysfunction, reflecting reduced brain capacity or reserve, patients with schizophrenia seemed to show relatively greater impairment in executive functions, 
and in learning and memory, related to frontotemporal dysfunction (Gold et al. 1992; Goldberg et al. 1987; McKenna et al. 1990; Saykin et al. 1991, 1994).

Neurocognitive measures can help address the following pivotal questions for understanding the pathophysiology of schizophrenia. When in the course of the illness do cognitive deficits emerge? Are they progressive? Do they relate to the symptoms that define the disorder? Are they affected by treatment and relate to outcome? Studies addressing these questions have indicated that: neurocognitive deficits are apparent at first clinical presentation in neuroleptic-naive patients (Bilder et al. 1992; Hoff et al. 1991; Saykin et al. 1994); while stable, some show improvement with treatment (Censits et al. 1997), especially with atypical neuroleptics (Buchanan et al. 1994; Daniel et al. 1996; Green et al. 1997; Hagger et al. 1993); and they show limited relation to clinical symptoms (Censits et al. 1997), but do relate to functional outcome (Bellack et al. 1999; Green 1996).

To achieve maximum benefit from neurocognitive measures in basic and clinical neuroscience, and in intervention, it is necessary to use tests that yield efficient and accurate performance data and that can be easily applied both in the laboratory setting and in clinical trials. Traditional paper-and-pencil batteries have several limitations, and we have described in the companion paper a computerized scan that may address them.

We present two studies aimed at examining the utility of the computerized scan in neurocognitive evaluation of schizophrenia. In study 1, we applied both the traditional and the computerized neurocognitive assessment to a sample of well-characterized patients with schizophrenia. This enabled a comparison of the resulting cognitive profiles in relation to sample characteristics. We hypothesized that the diffuse pattern of deficits evident in patients with the traditional battery will also be manifested in the computerized scan. The computerized scan permitted, in addition, an evaluation of whether patients are differentially affected in performance accuracy versus performance speed. In study 2, we extended the computerized scan to a new sample of patients to establish replicability of the neurocognitive profile. By combining the two patient samples, we also had the power to examine sex differences and correlations with clinical measures, which help establish construct and criterion validity.

\section{STUDY 1. COMPARISON OF TRADITIONAL BATTERY AND COMPUTERIZED SCAN: METHODS}

\section{Study 1: Subjects}

Participants were 53 patients with schizophrenia (34 men, 19 women) and 71 healthy controls (41 men, 30 women) from the Schizophrenia Center of The University of Pennsylvania. Healthy participants were selected from the larger sample presented in the companion article, to balance patients sociodemographically with respect to age and parental education. The groups did not differ (mean \pm SD) in age (patients $34.1 \pm 11.1$; controls $31.2 \pm 9.7$ ) or parental education (patients $12.9 \pm 3.2$; controls $12.2 \pm 4.2$ ), but, as expected, patients attained lower education $(13.4 \pm 2.3)$ than controls $(15.9 \pm 2.0), \mathrm{t}(120)=6.18, p<.0001$. Patients had a DSMIV diagnosis of schizophrenia established by medical, neurological, and psychiatric evaluations including clinical assessment, structured interview (SCID-P, First et al. 1996), history obtained from family, care providers, and records. Those with schizophreniform disorder at study entry met criteria for schizophrenia at followup. Participants had no history of any other disorder or event that might affect brain function. Age of onset of psychotic symptoms in the context of functional decline was $22.5 \pm 5.4$, and duration of illness was $10.4 \pm 9.5$ years. Patients were clinically stable at the time of study with mild to moderate symptoms (22 inpatients, 31 outpatients). There were 28 neuroleptic-naive and 25 previously treated patients: 13 patients ( $24 \%$ of sample) were on typical neuroleptics, and $9(17 \%)$ were on atypical agents at the time of testing.

\section{Study 1: Procedures}

Clinical and neurocognitive assessments were conducted within a week. After complete description of the study, written informed consent was obtained before participation. Assessments of symptoms and level of function were performed by trained reliable (ICC > 0.85) investigators (Gur et al. 1991). Symptom ratings included the Scales for Assessment of Negative Symptoms (SANS, Andreasen 1984a) and Positive Symptoms (SAPS, Andreasen 1984b). Premorbid Adjustment Scale (PAS, Harris 1975), and Quality of Life Scale (QOL, Henrichs et al. 1984) assessed functioning.

The traditional neuropsychological battery described in the companion paper (Gur et al. 2001) was administered to participants according to established procedures by trained predoctoral and postdoctoral Fellows (Censits et al. 1997; Ragland et al. 1999,2000; Saykin et al. 1991, 1994). The computerized neurocognitive scan was administered to all participants in a counterbalanced order within a week of each other. Patients remained clinically stable between the administration of both tests, and no changes in medications were introduced.

\section{Study 1: Data Analysis}

Test scores were standardized (z-scores; mean $=0$, standard deviation $=1$ ), based on all healthy participants in 
our normative database, and grouped into summary measures by combining each subject's z-scores on tests assessing the same functional domain (Censits et al. 1997; Saykin et al. 1991). For the traditional battery, summary measures were calculated for abstraction and mental flexibility (ABF), attention (ATT), verbal memory (VMEM), spatial memory (SMEM), language abilities (LAN), spatial abilities (SPA), sensory functions (SEN), and motor speed (MOT). For the computerized scans, facial memory (FMEM) was added, and sensorimotor (SM) skills were combined. The variables comprising these functions were presented in Tables 1 and 2 of the companion paper.
The hypotheses of impaired functioning and differential deficit were tested using a generalized estimating equations (GEE) model. The GEE procedure was preferred, because the repeated measures analysis of variance (ANOVA) model makes specific assumptions about the variance structure, through the sphericity assumption. This assumption is often not met, and the ANOVA model cannot accommodate generic correlation structures. In addition, in the current dataset, there are some missing data on individual subjects. Each subject with any missing test score is deleted in an ANOVA procedure, or imputed values are used, with each of these alternatives presenting unique problems. GEE is a more re-

Table 1. Neuropsychological Performance of Patients with Schizophrenia (SCH) and Healthy Controls (CNT) on the Traditional Battery

\begin{tabular}{|c|c|c|c|c|}
\hline \multirow[b]{2}{*}{ Cognitive Domain and Component Test Variables } & \multicolumn{2}{|c|}{$\mathrm{SCH}$} & \multicolumn{2}{|c|}{ CNT } \\
\hline & Mean & SD & Mean & SD \\
\hline \multicolumn{5}{|l|}{ Executive: Abstraction (ABF) } \\
\hline Percentage categories, $\mathrm{WCST}^{a}$ & 3.8 & 2.9 & 6.0 & 2.2 \\
\hline Percentage perseverative errors, $\mathrm{WCST}^{a}$ & 21.2 & 18.2 & 11.5 & 6.1 \\
\hline \multicolumn{5}{|l|}{ Attention (ATT) } \\
\hline Seashore rhythm, total correct, $\mathrm{HRB}^{b}$ & 24.7 & 4.7 & 27.8 & 2.3 \\
\hline Trails A time (s), $\mathrm{HRB}^{b}$ & 36.8 & 18.9 & 23.3 & 7.6 \\
\hline Trails B time (s), $\mathrm{HRB}^{b}$ & 104.8 & 71.1 & 53.5 & 17.5 \\
\hline Digit span and digit symbol, raw score, WAIS- $\mathrm{R}^{c}$ & 13.7 & 4.2 & 17.0 & 4.0 \\
\hline Vigilance, total correct, $\mathrm{CPT}^{d}$ & 27.3 & 4.8 & 29.5 & 1.3 \\
\hline \multicolumn{5}{|l|}{ Memory: Verbal memory (VMEM) } \\
\hline Logical memory immediate recall, WMS- $\mathrm{R}^{e}$ & 20.1 & 8.1 & 28.2 & 6.5 \\
\hline Logical memory delayed recall, WMS- $\mathrm{R}^{e}$ & 16.4 & 8.4 & 25.1 & 7.5 \\
\hline Learning trials 1 through $5, \mathrm{CVLT}^{f}$ & 45.3 & 13.6 & 60.5 & 9.3 \\
\hline \multicolumn{5}{|l|}{ Spatial memory (SMEM) } \\
\hline Design reproduction immediate recall, WMS- $\mathrm{R}^{e}$ & 30.8 & 7.2 & 36.1 & 3.8 \\
\hline Design reproduction delayed recall, WMS- $\mathrm{R}^{e}$ & 26.4 & 10.1 & 34.6 & 4.4 \\
\hline \multicolumn{5}{|l|}{ Intellectual: Language ability (LAN) } \\
\hline Controlled oral word association, $\mathrm{MAE}^{g}$ & 37.3 & 12.4 & 46.8 & 0.4 \\
\hline Animal naming, $\mathrm{BDAE}^{h}$ & 18.1 & 5.3 & 24.7 & 4.4 \\
\hline Reading sentences and paragraphs, $\mathrm{BDAE}^{h}$ & 8.9 & 1.6 & 9.8 & 0.5 \\
\hline Token test, 12 -item version, $\mathrm{MAE}^{g}$ & 21.2 & 3.6 & 23.1 & 1.6 \\
\hline Mattis aphasia exam visual naming & 46.9 & 9.3 & 52.9 & 5.9 \\
\hline \multicolumn{5}{|l|}{ Spatial ability (SPA) } \\
\hline Total correct, JOLO ${ }^{i}$ & 21.0 & 6.4 & 25.7 & 3.3 \\
\hline Block design, raw score, WAIS-R ${ }^{c}$ & 23.9 & 12.6 & 33.9 & 9.3 \\
\hline \multicolumn{5}{|l|}{ Sensorimotor: Sensory (SEN) } \\
\hline Stereognosis time (s), right hand, $\mathrm{LNNB}^{j}$ & 10.9 & 6.0 & 8.1 & 3.2 \\
\hline Stereognosis time (s), left hand, $\mathrm{LNNB}^{j}$ & 9.7 & 5.3 & 7.5 & 3.9 \\
\hline Stereognosis errors, right hand, LNNB ${ }^{j}$ & 0.2 & 0.4 & 0.1 & 0.5 \\
\hline Stereognosis errors, left hand, LNNB ${ }^{j}$ & 0.2 & 0.4 & 0.2 & 0.7 \\
\hline \multicolumn{5}{|l|}{ Motor (MOT) } \\
\hline Finger tapping, right hand, $\mathrm{HRB}^{b}$ & 46.1 & 7.8 & 47.9 & 7.1 \\
\hline Finger tapping, left hand, $\mathrm{HRB}^{b}$ & 43.1 & 7.0 & 43.9 & 7.8 \\
\hline
\end{tabular}

${ }^{a}$ WCST $=$ Wisconsin Card Sorting Test (Heaton 1981).

${ }^{b} \mathrm{HRB}=$ Halstead Reitan Battery (Reitan and Woltson 1985).

${ }^{c}$ WAIS-R $=$ Wechsler Adult Intelligence Scale-Revised (Wechsler 1981).

${ }^{d} \mathrm{CPT}=$ Continuous Performance Test (Gordon 1986).

${ }^{e}$ WMS-R = Wechsler Memory Scale-Revised (Wechsler 1987).

${ }^{f}$ CVLT $=$ California Verbal Learning Test (Delis et al. 1983).

8MAE = Multilingual Aphasia Exam (Benton and Hamsher 1976).

${ }^{h}$ BDAE $=$ Boston Diagnostic Aphasia Exam (Goodglass and Kaplan 1983).

${ }^{i}$ JOLO $=$ Judgment of Line Orientation (Benton et al. 1975).

${ }^{j}$ LNNB $=$ Luria-Nebraska Neuropsychological Battery (Golden et al. 1991). 
Table 2. Neuropsychological Performance of Patients with Schizophrenia (SCH) and Healthy Controls (CNT) on Computerized Neurocognitive Scan in Study 1

\begin{tabular}{|c|c|c|c|c|}
\hline \multirow[b]{2}{*}{ Cognitive Domain and Component Test Variables } & \multicolumn{2}{|c|}{$\mathrm{SCH}$} & \multicolumn{2}{|c|}{ CNT } \\
\hline & Mean & SD & Mean & SD \\
\hline \multicolumn{5}{|l|}{ Executive: Abstraction/flexibility (ABF) } \\
\hline Abstraction inhibition and working memory, $\mathrm{AIM}^{a}$ & 39.5 & 7.9 & 46.4 & 7.7 \\
\hline Penn inhibition test, PIT & 12.0 & 5.4 & 14.0 & 2.6 \\
\hline Computerized ravens progressive matrices, $\mathrm{CRPM}^{b}$ & 37.1 & 12.9 & 46.0 & 10.0 \\
\hline \multicolumn{5}{|l|}{ Attention (ATT) } \\
\hline Penn continuous performance test, $\mathrm{PCPT}^{c}$ & 28.8 & 11.8 & 34.6 & 7.1 \\
\hline Computerized stroop test, $\mathrm{CSTR}^{d}$ & 29.9 & 7.5 & 35.3 & 1.1 \\
\hline \multicolumn{5}{|l|}{ Memory: Verbal memory (VMEM) } \\
\hline Penn word memory test PWMT ${ }^{e}$ & 31.2 & 5.6 & 35.6 & 3.0 \\
\hline \multicolumn{5}{|l|}{ Facial memory (FMEM) } \\
\hline Penn face memory test $\mathrm{PFMT}^{e}$ & 27.9 & 4.2 & 33.2 & 2.7 \\
\hline \multicolumn{5}{|l|}{ Spatial memory (SMEM) } \\
\hline Visual object learning test, VOLT $^{f}$ & 57.8 & 11.8 & 68.8 & 10.9 \\
\hline \multicolumn{5}{|l|}{ Intellectual: Language (LAN) } \\
\hline Penn verbal reasoning test, PVRT $^{g}$ & 48.8 & 25.1 & 69.3 & 16.9 \\
\hline \multicolumn{5}{|l|}{ Spatial (SPA) } \\
\hline Computerized Benton line orientation test, $\mathrm{CJOLO}^{h}$ & 20.9 & 6.4 & 23.5 & 5.4 \\
\hline \multicolumn{5}{|l|}{ Sensorimotor ability (SM) } \\
\hline Pursuit rotor task PRT $^{i}$ & -1.9 & 5.6 & -5.9 & 8.7 \\
\hline $\begin{array}{l}{ }^{a} \text { AIM (Glahn et al. 2000). } \\
{ }^{b} \text { CRPM (Raven 1960). } \\
{ }^{c} \text { PCPT (Kurtz et al. 2001). } \\
{ }^{d} \text { CSTR (Stroop 1935). } \\
{ }^{e} \text { PWMT and PFMT (Gur et al. 1993). } \\
f^{f} \text { VOLT (Glahn et al. 1997). } \\
{ }^{8} \text { PVRT (Gur and Reivich 1980). } \\
{ }^{h} \text { CJOLO (Benton et al. 1975). } \\
{ }^{i} \text { PRT. } \\
{ }^{j} \text { (Chute and Westall 1997). }\end{array}$ & & & & \\
\hline
\end{tabular}

cent methodology for the analysis of longitudinal or clustered data, and allows this model (as well as many other models) to be fit without any imputation of missing datapoints and without deleting subjects with some test scores missing. It also allows for many correlation structures between the test scores, including the ability to estimate this correlation structure rather than make assumptions (Diggle et al. 1994; Zeger and Liang 1986). The GEE method does assume that the number of subjects is large relative to the number of test scores measured on each subject, which is the case in the current dataset.

The GEE was applied with diagnosis as a grouping factor and functional domain as a within-group (repeated measures) factor. Differential deficit would be indicated by a diagnosis $\times$ function interaction. The GEE on the computerized scores were performed separately for accuracy and speed.

To compare the ability of the two approaches to classify participants into patient and control groups, we used ROC analysis (Hanley and McNeil 1982; Metz 1978; Peterson et al. 1954) to determine the cut-off points yielding sensitivity and specificity for the frontotemporal index (average of ABF, ATT, VMEM, and SMEM for the traditional battery and FMEM added to the computerized scan).

\section{STUDY 1: RESULTS}

Patients had, on average, a mild-to-moderate premorbid course, with women rating better on the PAS, $t$ $(122.2)=3.91, p<.001$ (df for unequal variances because $\left.\mathrm{F}^{\prime}(74,54)=2.97, p<.001\right)$. The SAPS and SANS ratings likewise reflected mild-to-moderate severity of illness. Although men and women did not differ on the SAPS, women had lower severity of negative symptoms on the SANS, $\mathrm{t}(128)=2.30, p<.025$. Women were also less impaired on the QOL ratings, $\mathrm{t}(128)=2.24, p<$ .05 , all two-tailed.

The means of patients with schizophrenia and healthy participants on the traditional battery and the computerized scan are presented in Tables 1 and 2, respectively. For comparability across tests and domains, further analyses were performed on the z-transformed data.

\section{Study 1: Diagnosis Effects}

The profiles of patients with schizophrenia (Figure 1) on the traditional battery (top bar) and the computerized scan accuracy (middle bar) and speed (bottom bar) indicated generalized diffuse impairment for patients using both methods. On the traditional battery, patients 


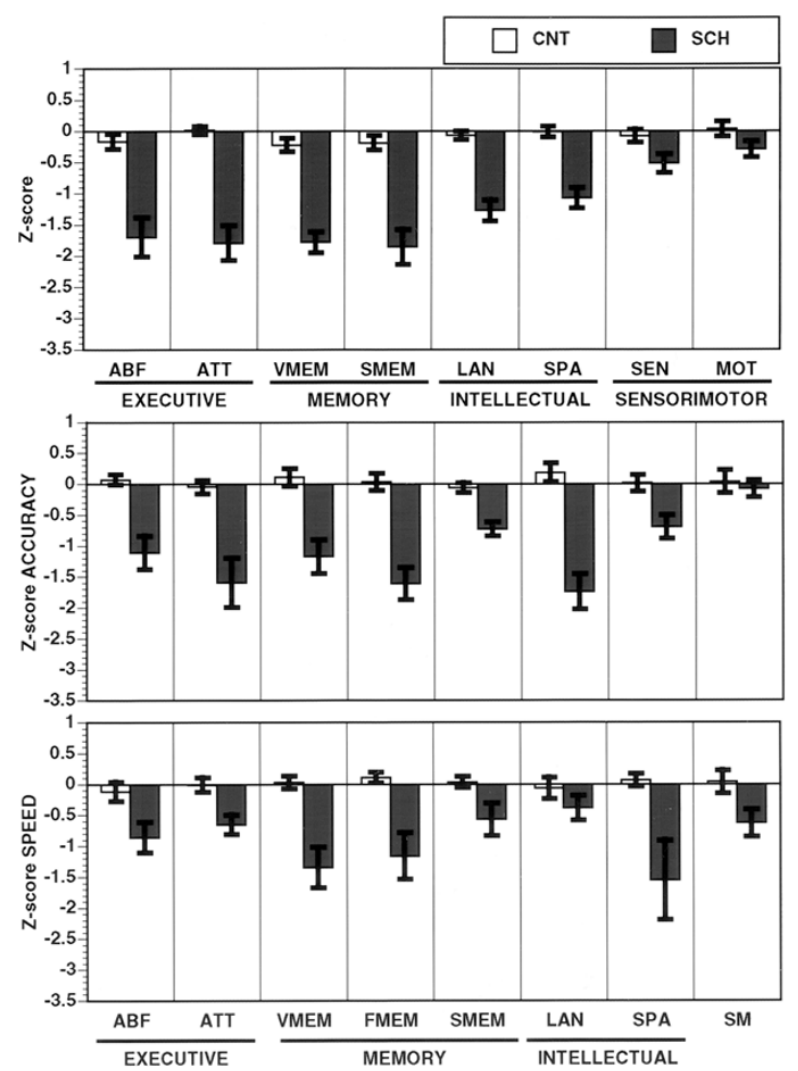

Figure 1. The neurocognitive profile of Study 1 patients with schizophrenia and healthy controls (means \pm SEM) on the traditional battery (top bar) and the computerized scan accuracy (middle) and speed (bottom).

with schizophrenia showed pronounced uniform impairment; whereas, for the computerized scan, they were impaired in all but the sensorimotor domain.

The GEE for the traditional battery domains showed main effects of diagnosis, $\chi^{2}(1)=217.64, p=.0001$, domain, $\chi^{2}(7)=25.77, p=.0006$, and a diagnosis $\times$ domain interaction, $\chi^{2}(7)=17.52, p=.01$, demonstrating differential deficit. The same GEE model applied to the computerized scan accuracy scores showed main effects of diagnosis, $\chi^{2}(1)=91.03, p=.0001$, domain, $\chi^{2}(7)=$ $18.29, p=.01$, and a diagnosis $\times$ domain interaction, $\chi^{2}(7)=17.62, p=.01$, also demonstrating differential deficit. For the computerized scan speed scores, the GEE also showed main effects of diagnosis, $\chi^{2}(1)=39.04, p=$ .0001 , domain, $\chi^{2}(7)=14.41, p=.04$, and a diagnosis $\times$ domain interaction, $\chi^{2}(7)=17.52, p=.01$.

To limit the number of post-hoc analyses to decompose the significant diagnosis $\times$ domain interactions, we tested specifically the hypothesis that the differential deficit is in executive and memory functions relative to the other domains. For the traditional battery, the frontotemporal score was the average of ABF, ATT, VMEM, and SMEM, and the average of the remaining domains was subtracted from it to provide a differen- tial deficit index (the higher the score, the better the individual performs in executive and memory domains relative to the other domains). A similar index was calculated for the computerized scan by defining the frontotemporal score as the average of ABF, ATT, WMEM, FMEM, and SMEM and subtracting from it the average of the remaining domains. The hypothesis of differential deficit in executive-memory functions was supported for the traditional battery in that the differential deficit index was significantly lower than zero for patients, $-0.99 \pm 1.03, \mathrm{t}(51)=6.95, p<.0001$, but not in healthy comparison subjects, $-0.10 \pm 0.58, \mathrm{t}(69)=1.58$, $p=.1187$, and the difference between patients and controls is statistically significant, $\mathrm{t}(75.6)=5.59, p<.0001$ (the $\mathrm{df}$ was corrected for unequal variances). Similarly for the accuracy scores of the computerized scan, the differential deficit index was significantly negative for patients, $-0.57 \pm 1.83, \mathrm{t}(51)=3.04, p=.003$, but not controls, $0.00 \pm 0.84, \mathrm{t}(69)=0.00, p=.9982$, and the difference between the groups was significant, $t(75.6)=$ $2.72, p=.0093$. Thus, both approaches indicated differential deficit in neurobehavioral domains associated with frontotemporal functioning.

The ROC analysis for the traditional battery yielded area under the curve of 0.86 and suggested a cut-off point of $\mathrm{z}=-0.50$ as providing a sensitivity of 0.81 and a specificity of 0.73 . The ROC analysis for the computerized battery yielded area under the curve of 0.84 and suggested a cut-off point of $\mathrm{z}=-0.80$ as providing a sensitivity of 0.81 and a specificity of 0.74 . The classification of individuals into impairment groups showed close agreement. The traditional battery classified 39 of the 53 patients and 15 of the 71 controls as impaired; whereas, the computerized scan classified the same 39 patients and 12 of the same controls as impaired.

\section{STUDY 1: DISCUSSION}

The traditional battery and the computerized scan showed in general comparable results, supporting generalized impairment in schizophrenia with deficits in executive functions and memory (Calev et al. 1983; Gold et al. 1992; Goldberg et al. 1987; McKenna et al. 1990; Saykin et al. 1991, 1994). Both approaches generated scores that were sensitive to the presence of schizophrenia and showed differential deficits with high levels of significance.

It is also noteworthy that the patients tolerated the computerized scan well. In contrast to the traditional battery, which taxes patients' endurance, patients seemed to appreciate the brevity of the computerized scan. They did not have difficulties operating the computer and informally they appeared more relaxed being tested by a computer rather than a person. Therefore, 
we believe that this study has demonstrated adequate feasibility for application in schizophrenia.

\section{STUDY 2. THE COMPUTERIZED SCAN NEU- ROCOGNITIVE PROFILE OF SCHIZOPHRENIA: SEX DIFFERENCES AND CLINICAL CORRE- LATES: METHODS}

\section{Study 2: Subjects}

A new sample of 68 patients with schizophrenia (44 men, 24 women) and 37 healthy controls (18 men, 19 women) from the Schizophrenia Center of The University of Pennsylvania participated in this study. Procedures for recruitment and diagnosis were identical to Study 1 . The groups did not differ (mean \pm SD) in age (patients $33.8 \pm 12.4$; controls $32.0 \pm 14.0$ ) or parental education (patients $13.2 \pm 3.5$; controls $13.4 \pm 3.8$ ), but, as expected, patients attained lower education (12.8 \pm 2.2) than controls $(15.3 \pm 2.1), \mathrm{t}(103)=5.25, p<.0001$. Age of onset of psychotic symptoms in the context of functional decline was $23.5 \pm 7.4$ and duration of illness was $9.6 \pm 10.1$ years. Patients were clinically stable at the time of study with mild to moderate symptoms (33 inpatients, 35 outpatients). There were 37 neurolepticnaive and 31 previously treated patients: $21(31 \%)$ patients were on typical neuroleptics, and $8(12 \%)$ patients were on atypical agents at the time of testing. The patient sample in Study 2 did not differ from the sample in Study 1 in age, education, parental education, age of onset, or duration of illness.

\section{Study 2: Procedures}

Clinical and neurocognitive assessments were detailed in Study 1. Only the computerized neurocognitive scan was administered to participants in Study 2.

\section{Study 2: Data Analysis}

Test scores were calculated as in Study 1. The hypotheses of impaired functioning and differential deficit were tested using a GEE model, with diagnosis as a grouping factor and functional domain as a within-group (repeated measures) factor. Differential deficit would be indicated by a diagnosis $\times$ function interaction. The GEEs were performed separately for accuracy and speed. The classification using a cut-off z-score of -0.5 on the frontotemporal measures was repeated as in Study 1.

The ROC derived classification criteria from the first sample were used to determine replicability on the second. Thus, the cut-off scores of $\mathrm{z}=-0.8$ was used again for the index of frontotemporal functioning, as in Study 1.

The combined patient sample, of Studies 1 and 2, was examined for sex differences by entering sex as a grouping factor in a sex $\times$ diagnosis GEE model. The effects of medication were examined by contrasting neuroleptic naive with previously treated patients and by correlating performance on the functional domains with average daily lifetime dose of typical and atypical neuroleptics.

This combined sample was also used to examine the associations with clinical measures of symptoms and functioning following established procedures (Censits et al. 1997; Gur et al. 1999). The performance on each neurocognitive domain was correlated with PAS, duration of illness, severity of global SANS and SAPS, and QOL. These correlations were calculated separately for men and women. To examine possible sex differences in these correlations, we developed and applied a nonparametric method for testing the significance of differences in correlations both between groups and withingroup by domain. Parametric methods exist for testing the significance of a difference between two or more correlations taken from different samples, the Fisher-z procedure and various extensions to more than two correlations. However, until fairly recently, no procedures existed for testing the significance of a difference between two correlations obtained from the same sample ("correlated correlations"). One such procedure for testing whether the correlations among a set of measurements with a common variable are homogeneous was developed by Olkin and Finn (1990). The difficulty of this problem is that the correlations all involve a common variable. In our case, this would apply to testing the homogeneity of the correlations of clinical variables (premorbid adjustment, duration of illness, etc.) with each of the neuropsychological domain scores (executive functions, memory, intellectual, and sensorimotor functions). Our method conceptualizes these contrasts in the context of a one-way ANOVA, but instead of asking whether the means differ for the neuropsychological domains, our question is whether the correlations with the clinical variable differ. Thus, we can represent the correlated correlations as one withingroup factor. This CORANOVA procedure simultaneously tests the effects for a within factor, a between factor, and the interaction of these two factors, which is analogous to a two-way ANOVA for correlated correlations. In our case, the within factor is neurocognitive domain, and the between factor is sex. In addition to extending the Olkin and Fin method, which is parametric and depends on asymptotic normality and hence large sample sizes, our method is completely nonparametric. The properties of this procedure have been carefully checked through a systematic series of intensive computer simulations, and we found that the power is quite good (Bilker et al. submitted). Consider the case where all correlations of a clinical variable with each neuropsychological domain score are same except for one that differs between men and women by two standard devi- 
Table 3. Neuropsychological Performance of Patients with Schizophrenia (SCH) and Healthy Controls (CNT) on the Computerized Neurocognitive Scan in Study 2 (abbreviations as in Table 2)

\begin{tabular}{|c|c|c|c|c|}
\hline \multirow[b]{2}{*}{ Domain and Test } & \multicolumn{2}{|c|}{$\mathrm{SCH}$} & \multicolumn{2}{|c|}{ CNT } \\
\hline & Mean & SD & Mean & SD \\
\hline \multicolumn{5}{|l|}{ Executive: $\mathrm{ABF}$} \\
\hline AIM & 40.9 & 10.4 & 48.3 & 5.9 \\
\hline PIT & 12.5 & 4.0 & 14.6 & 1.4 \\
\hline CRPM & 35.3 & 12.7 & 46.8 & 6.9 \\
\hline \multicolumn{5}{|l|}{ ATT } \\
\hline PCPT & 29.8 & 8.9 & 34.5 & 3.8 \\
\hline CSTR & 32.4 & 4.7 & 35.2 & 1.8 \\
\hline \multicolumn{5}{|l|}{ Memory: WMEM } \\
\hline PWMT & 32.8 & 4.5 & 36.4 & 2.6 \\
\hline \multicolumn{5}{|l|}{ FMEM } \\
\hline PFMT & 28.8 & 4.7 & 33.6 & 3.0 \\
\hline \multicolumn{5}{|l|}{ SMEM } \\
\hline VOLT & 58.0 & 11.5 & 69.0 & 6.3 \\
\hline \multicolumn{5}{|l|}{ Intellectual: LAN } \\
\hline PVRT & 47.6 & 21.0 & 76.2 & 13.1 \\
\hline \multicolumn{5}{|l|}{ SPA } \\
\hline CJOLO & 20.0 & 6.2 & 23.9 & 5.4 \\
\hline \multicolumn{5}{|l|}{ Sensorimotor: SM } \\
\hline PRT & -6.0 & 6.6 & -4.9 & 10.1 \\
\hline
\end{tabular}

ations. The interaction of the within and between factors can be detected with a power of $84 \%$ for sample sizes of 75 for each gender group and a power of $43 \%$ with just 15 per cell.

\section{STUDY 2: RESULTS}

Patients had, on average, a mild-to-moderate premorbid course (PAS men $=2.1 \pm 1.2$, range $=0.2-4.3$; women $=1.2+0.6$, range $=0.2-2.0)$, with women doing better, $\mathrm{t}(32.6)=2.9, p<.01(\mathrm{df}$ for unequal variances because $\left.\mathrm{F}^{\prime}(22,11)=4.9, p<.01\right)$. The SAPS and SANS ratings, likewise, reflected mild-to-moderate severity of illness. Men and women did not differ on the SAPS. However, men had more severe over-all symptoms on the SANS, $\mathrm{t}(64)=2.82, p<.01$. Women also had higher QOL ratings, $\mathrm{t}(60)=2.10, p<.05$. The means for this sample do not differ from those of Study 1 for PAS, SAPS, and QOL. However, the present sample had more severe negative symptoms (SANS total Study 1: $24.57 \pm 17.52$; Study 2: $34.47 \pm 19.73), \mathrm{t}(107)=2.28, p<$ .025 .

The means of the new sample of patients and healthy participants on the computerized scan are presented in Table 3, and the neurocognitive profile is illustrated in Figure 2. As can be seen, the profile of this sample is similar to that of the first sample for accuracy and speed, although patients from the new sample performed more poorly on Attention and Abstraction.

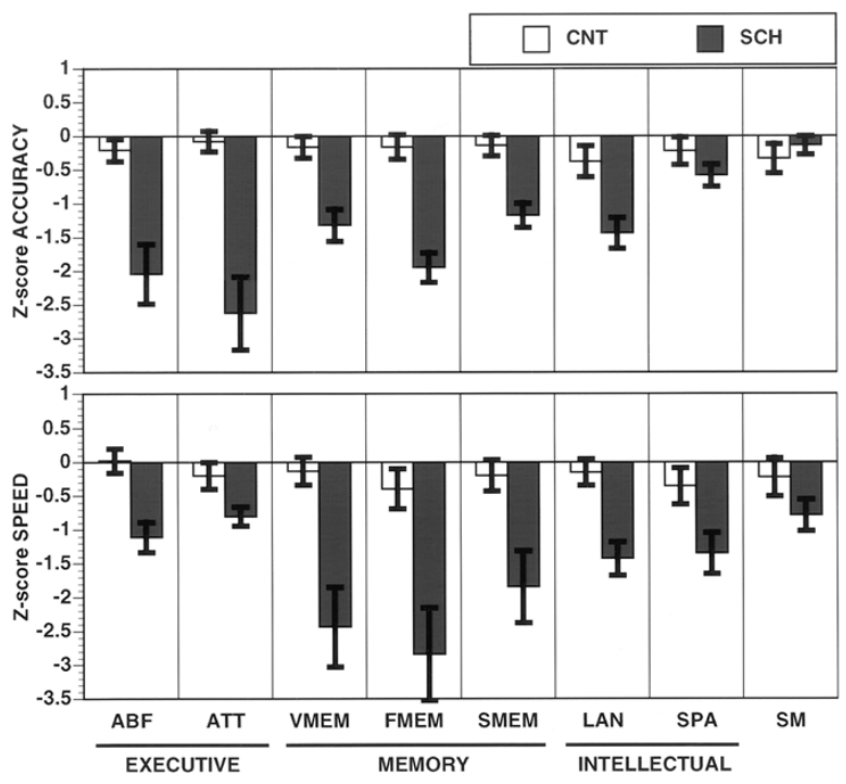

Figure 2. The neurocognitive profile of Study 2 patients with schizophrenia and healthy controls (means \pm SEM) on the computerized scan accuracy (top) and speed (bottom).

The GEE model applied to the accuracy scores showed main effects of diagnosis, $X^{2}(1)=86.16, p=.0001$, domain, $X^{2}(7)=46.03, p=.0001$, demonstrating differential deficit. For the speed scores, the GEE also showed main effects of diagnosis, $\mathrm{X}^{2}(1)=82.34, p=.0001$, domain, $X^{2}(7)=27.16, p=.0443$, and a diagnosis $\times$ domain interaction, $X^{2}(7)=27.15, p=.0003$. Adding sex to the model on the combined sample did not produce additional significant main effects or interactions. However, women with schizophrenia were less impaired than men in VMEM accuracy, $\mathrm{t}=1.93, \mathrm{df}=119, p<$ .05 , and more impaired in spatial processing accuracy, $\mathrm{t}=2.65, p<.01$ (Figure 3). Likewise, adding medication status as a grouping factor did not show differences between neuroleptic naive and previously treated patients. Sample size did not permit examination of typical and atypical neuroleptics separately as grouping factors and did not permit crossing sex with medication status.

Classification of subjects by the cutoff z-score of -0.8 on the frontotemporal index placed 48 of the 68 patients and 7 of the 37 controls in the new sample as impaired, yielding a sensitivity of 0.71 and a specificity of 0.81 . The sensitivity estimate is somewhat lower than the 0.81 obtained for the first sample that had both the traditional battery and the computerized scan; whereas, the specificity estimate is higher than the 0.73 obtained for that sample.

Although there were no significant differences between neuroleptic naive and previously treated patients in average performance, within the treated group, higher average daily dose of neuroleptics was associ- 


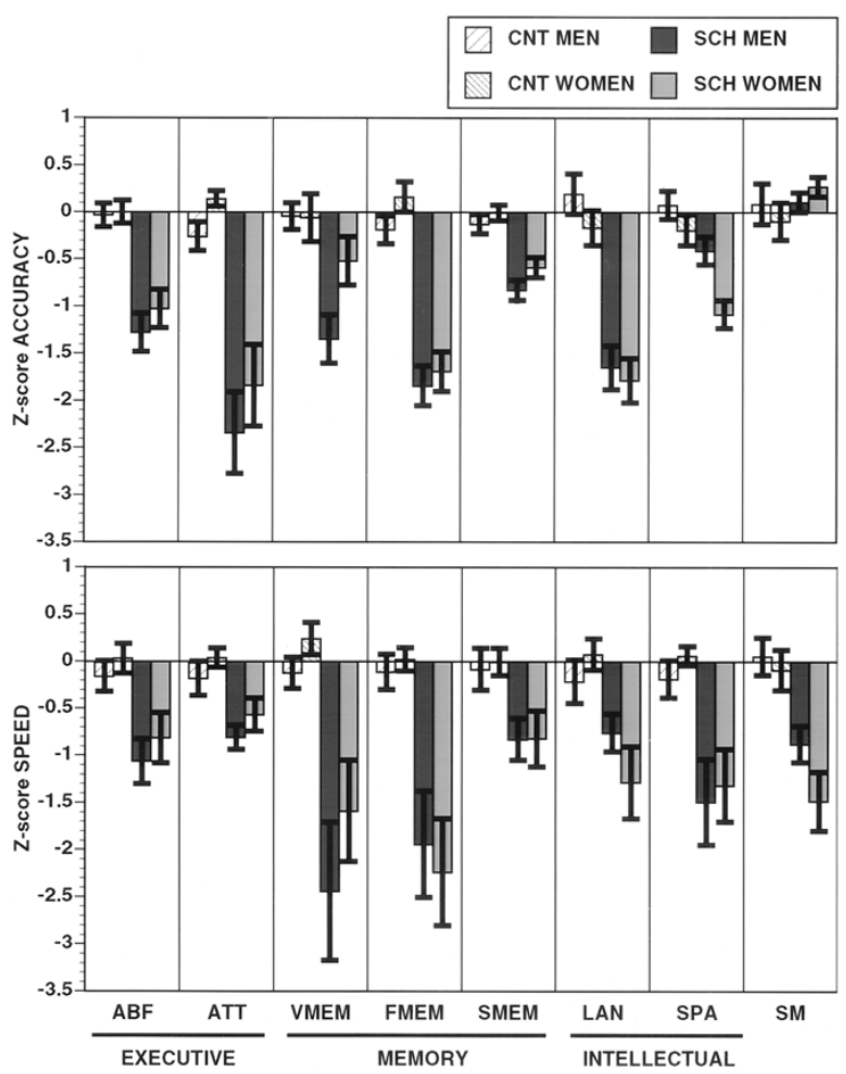

Figure 3. The neurocognitive profile of the combined sample of men and women with schizophrenia and health controls (means \pm SEM) on the computerized scan accuracy (top) and speed (bottom).

ated with poorer performance on specific domains. Correlations were significant in men between typical neuroleptic dose and SM accuracy, $\rho=-.43$ and speed for the memory tasks: VMEM, $\mathrm{r}=-0.46$, FMEM, $\mathrm{r}=-0.43$, and SMEM, $\mathrm{r}=-0.38$, all $p<.01$. No other correlations with dose of typical neuroleptics, and none with dose of atypical neuroleptics, approached significance. In women, dose of typical neuroleptics was correlated with speed VMEM, $\mathrm{r}=-0.63$, and FMEM, $\mathrm{r}=-0.56$, both $p<.001$. For these domains, correlations with dose of atypical neuroleptics were smaller but also significant, speed VMEM, $\mathrm{r}=-0.60, p<.001$ and FMEM, $\mathrm{r}=-0.40, p<$ .05 . No other correlations between neuroleptic dose and neurocognitive domains approached significance.

The correlations between the domain scores from the traditional battery and comparable "efficiency" scores from the computerized battery are presented for patients in Table 4. As for healthy participants in the companion paper, the correlations between comparable domains (diagonal) are moderate to high for all but the sensorimotor function. However, unlike healthy controls who show no correlations for noncompatible domains, in patients we observe correlations with other domains.

The correlation between neurocognitive domains and clinical measures, calculated for the combined sample, are presented in Table 5 . As can be seen, while the correlations are generally modest, all but one of the significant correlations were in the expected direction, negative for PAS, duration, and symptoms, and positive for age at onset and for function (QOL). However, they seemed higher and more ubiquitous in women. The CORANOVA performed to test the homogeneity of correlations in males and females formally showed no significant sex differences or sex $\times$ domain interactions for the correlations with PAS. For age at onset, there was a main effect of sex on accuracy measures, $p=.034$, indicating over-all higher correlations for women than men, with no significant differences in correlations with speed. For duration of illness, there was a main effect of sex on accuracy correlations, $p=.01$, indicating higher correlations for women. The sex $\times$ domain interaction was marginal for accuracy, $p=.064$, but significant for speed, $p=.044$, reflecting the greater contribution of executive and memory correlations to this effect. For quality of life correlations, there was a main effect of sex for the accuracy correlations, $p=$ .05 , again reflecting stronger over-all correlations in women; whereas, for speed, there was a main effect for domain, $p=.022$, reflecting variability of correlations, depending on domain. For the SANS total score, there was a significant sex $\times$ domain interaction for correlations with

Table 4. Correlations Between the Traditional Measures of Major Cognitive Domains and the Computerized "Efficiency" Measures for the Comparable Domains

\begin{tabular}{llllcc}
\hline & & \multicolumn{4}{c}{ Computerized } \\
\cline { 3 - 5 } Traditional & & Executive & Memory & Intellectual & Sensorimotor \\
\hline Executive & $\mathrm{r}$ & $\mathbf{0 . 5 2}$ & 0.48 & 0.46 & -0.04 \\
& $\mathrm{p}$ & 0.0001 & 0.0002 & 0.0023 & 0.8359 \\
Memory & $\mathrm{r}$ & 0.60 & $\mathbf{0 . 5 3}$ & 0.65 & 0.13 \\
& $\mathrm{p}$ & 0.0001 & 0.0001 & 0.0001 & 0.4101 \\
Intellectual & $\mathrm{r}$ & 0.61 & 0.45 & $\mathbf{0 . 6 2}$ & 0.18 \\
Sensorimotor & $\mathrm{p}$ & 0.0001 & 0.0042 & 0.0001 & 0.2185 \\
& $\mathrm{r}$ & 0.55 & 0.40 & 0.46 & -0.15 \\
& $\mathrm{p}$ & 0.0001 & 0.0121 & 0.0023 & 0.3189 \\
\hline
\end{tabular}


Table 5. Correlations Between Clinical Measures and Performance on Accuracy (ACC) and Speed (SPD) Parameter of the Neurocognitive Scan; Significant Correlations are Boldface ${ }^{a}$

\begin{tabular}{|c|c|c|c|c|c|c|c|c|c|c|c|c|}
\hline \multirow[b]{3}{*}{ Cognitive Domain } & \multicolumn{12}{|c|}{ Scale } \\
\hline & \multicolumn{2}{|c|}{ PAS } & \multicolumn{2}{|c|}{ Onset } & \multicolumn{2}{|c|}{ DUR } & \multicolumn{2}{|c|}{ QOL } & \multicolumn{2}{|c|}{ SANS } & \multicolumn{2}{|c|}{ SAPS } \\
\hline & $\mathrm{ACC}$ & SPD & ACC & SPD & ACC & SPD & $\mathrm{ACC}$ & SPD & ACC & SPD & ACC & SPD \\
\hline \multicolumn{13}{|l|}{ Executive } \\
\hline Men & -0.00 & -0.21 & -0.09 & 0.09 & 0.05 & -0.14 & 0.19 & 0.49 & -0.21 & -0.30 & -0.09 & -0.14 \\
\hline Women & -0.45 & -0.24 & 0.31 & 0.42 & -0.56 & -0.25 & 0.35 & 0.47 & -0.26 & -0.13 & -0.13 & 0.10 \\
\hline \multicolumn{13}{|l|}{ Memory } \\
\hline Men & -0.15 & -0.18 & 0.03 & 0.06 & -0.02 & -0.17 & 0.04 & 0.22 & -0.10 & -0.05 & 0.02 & -0.05 \\
\hline Women & -0.02 & 0.26 & 0.41 & 0.11 & -0.37 & -0.42 & 0.44 & 0.17 & -0.50 & -0.16 & -0.16 & -0.05 \\
\hline \multicolumn{13}{|l|}{ Intellectual } \\
\hline Men & -0.13 & -0.19 & -0.05 & -0.09 & 0.00 & -0.35 & 0.32 & 0.10 & -0.17 & -0.01 & 0.08 & 0.05 \\
\hline Women & -0.14 & -0.28 & 0.18 & -0.22 & -0.26 & 0.14 & 0.37 & 0.41 & -0.52 & -0.25 & -0.20 & -0.47 \\
\hline \multicolumn{13}{|l|}{ Sensorimotor } \\
\hline Men & -0.25 & -0.13 & -0.05 & -0.12 & -0.15 & -0.03 & 0.09 & 0.40 & 0.01 & -0.23 & 0.25 & -0.17 \\
\hline Women & $0.42^{a}$ & 0.10 & 0.10 & -0.32 & -0.05 & -0.32 & 0.18 & 0.03 & -0.07 & 0.16 & 0.04 & 0.24 \\
\hline
\end{tabular}

Performance on Accuracy (ACC) and Speed (SPD) Parameter of the Neurocognitive Scan; Significant Correlations are Boldface

${ }^{a}$ Significant in the opposite direction.

accuracy, reflecting the higher correlations in women for memory and intellectual domains. This interaction was also significant for SAPS correlations with speed, $p=$ .024, reflecting the specifically high correlation in women for the intellectual domain. No other main effects or interactions were significant in the CORANOVA.

\section{STUDY 2: DISCUSSION}

In a second sample of patients with schizophrenia, we replicated the profile obtained with the neurocognitive scan. Again, the results demonstrated differential deficit, as indicated by the significant diagnosis by functional domain interaction, with memory being most consistently impaired both for speed and for accuracy. Executive functions, including abstraction and attention, were markedly more impaired for accuracy than for speed. The use of the frontotemporal index for classification of subjects yielded nearly identical sensitivity and specificity estimates for the two samples. Thus, we may conclude that the computerized approach to neurocognitive characterization of schizophrenia is feasible and yields reproducible data.

An exception to the identity of domain scores between the two samples was that the Study 2 patient sample had poorer performance on the face memory speed variable. This could possibly relate to their more severe negative symptoms, because the samples did not differ on other demographic or clinical measures. However, the correlation between performance on face memory and the SANS was not significant. Correlations were noted between performance and several clinical variables. In general, these correlations were in the expected direction of poorer performance associated with earlier age of onset, lower premorbid adjust- ment, longer illness duration, poorer quality of life, and more severe symptoms, particularly negative. However, although the over-all profile was similar in men and women with schizophrenia, the correlations between neurocognitive performance and clinical measures were more ubiquitous and higher for women. This sample manifested the clinical features that have been reported to differ for men and women with schizophrenia, including earlier age of onset and more severe negative symptoms in men (Angermeyer et al. 1990; Gur et al. 1996; Häfner et al. 1993). On the other hand, with the exception of verbal memory, in which women with schizophrenia were less impaired than men, women were equally impaired as men in both speed and accuracy of performance and were more impaired than men for spatial accuracy. This differs from some reports of less neurocognitive impairment in women than men with schizophrenia (Goldstein et al. 1998; Hoff et al. 1996), or more impairment in women than men (Lewine et al. 1996), but is consistent with earlier reports from our center (Gur et al. 1997; Ragland et al. 2001) reporting similar impairment in male and female patients. The difference favoring women with schizophrenia for verbal memory and men for spatial processing may reflect normal sex differences in these domains (Bleecker et al. 1988; Gur et al. 1999a,2001; Kimura and Harshman 1984; Kramer et al. 1988). Thus, it seems that although clinical measures favoring women do correlate with neurocognitive functioning, the effect is not sufficient to produce a group difference in neuropsychological performance. Possibly sample fluctuations may determine whether sex differences are obtained beyond what is expected from those evident in healthy populations.

The lack of difference in over-all severity and pattern of neurocognitive profile between neuroleptic naive and 
previously treated patients confirms earlier reports (Bilder et al. 1992; Gur et al. 1998, 1999b; Hoff et al. 1991; Saykin et al. 1994). This indicates that diffuse and significant cognitive deficits are evident at first clinical presentation before initiation of treatment. Nonetheless, higher medication exposure since treatment initiation is associated with worse performance, specifically in the speed of memory processing. This is consistent with our earlier report using the traditional neuropsychological battery, where we found in a longitudinal design that higher neuroleptic dose was associated with poorer memory and reduced volume in the temporal lobe (Gur et al. 1998). In our earlier study, we found this process to be limited to typical neuroleptics. In the present study, this was the case for men. However, for women, although the correlations were somewhat diminished, they were significant for both typical and atypical agents. The sample in the previous study was not large enough to examine sex differences. The present sample is still too small to permit evaluation of whether specific atypical agents are differentially associated with reduced memory speed. Longitudinal studies are needed to ascertain whether continued course of illness and treatment are associated with further decline.

The performance data generated by the computerized scan also demonstrated sensitivity to clinical variables including premorbid adjustment, age of onset, illness duration, quality of life, and symptom severity. All but two of the significant correlations were in the expected direction of better performance associated with a more favorable clinical status. As in the case of medication dose, these correlations were more prevalent and higher for women than for men. Furthermore, in men, clinical variables related predominantly to speed rather than accuracy of processing; whereas, in women, they related to both speed and accuracy. Thus, it seems that the neurocognitive performance measures of women are more sensitive to the effects of clinical variables; whereas, in men, variability related to clinical factors primarily influences speed of processing. Our results are consistent with earlier studies both in showing small-to-moderate correlations between neurocognitive measures and clinical variables (Censits et al. 1997) and in suggesting that gender moderates these relationships (Goldstein et al. 1998). The possibility that these variables affect speed more than accuracy in men merits further investigation.

\section{SUMMARY}

The application of brief computerized tests to scan neurocognitive functioning in schizophrenia provides a time-efficient procedure for obtaining reliable data. These data show comparable effects to those obtained with the traditional neuropsychological battery. The measures generated by the computerized scan seem to relate meaningfully to clinical variables including symptoms, function, and medications. The reproducibility of results in two samples supports the reliability of the neurocognitive scan, the pattern of correlations with age and clinical variables support its "construct validity" (Cronbach and Meehl 1955), and sensitivity and specificity results provide some "criterion validity" for the method. Using this new approach, we have replicated earlier reports based on the traditional battery and have also observed new phenomena afforded by the ability to separate accuracy and speed. Such procedures can complement efforts to develop abbreviated neurocognitive testing using traditional measures (Gold et al. 1999; Hobart et al. 1999).

The present studies were limited by their cross-sectional design, which did not permit determination of whether the observed correlations reflect progression of illness or its treatment. However, with efficient measurement tools, such as the computerized neurocognitive scan, longitudinal designs are feasible. The present study is also limited to people with schizophrenia who have mild-to-moderate symptoms. Future studies are needed to assess patients from more diverse settings and a wider range of symptom severity. Furthermore, the specificity of findings needs to be established as other neuropsychiatric disorders are examined.

\section{ACKNOWLEDGMENTS}

This research was supported by NIH Grants MH-43380, MH42191, MH-01336, MH-53326, MO1RR0040, the EJLB Foundation, and the Bosworth Family Fund. We thank Miriam Trelka, B.A., Shannan Smith, B.A., and the dedicated Schizophrenia Center staff and research participants.

\section{REFERENCES}

Andreasen NC (1984a): The Scale for the Assessment of Negative Symptoms (SANS). Iowa City, IA: University of Iowa Press

Andreasen NC (1984b): The Scale for the Assessment of Positive Symptoms (SAPS). Iowa City, IA: University of Iowa Press

Angermeyer MC, Kuhn L, Goldstein JM (1990): Gender and the course of schizophrenia: Differences in treated outcomes. Schizophr Bull 16:293-307

Bellack AS, Gold JM, Buchanan RW (1999): Cognitive rehabilitation for schizophrenia: Problems, prospects, and strategies. Schizophr Bull 25:257-274

Benton AL, Hamsher K (1976): Multilingual Aphasia Examination. Iowa City, IA: University of Iowa Press

Benton AL, Hannay JJ, Varney NR (1975): Visual perception of line direction in patients with unilateral brain disease. Neurology 25:907-910 
Bilder RM, Lipschutz-Broch L, Reiter G, Geisler SH, Mayerhoff DI, Lieberman JA (1992): Intellectual deficits in first-episode schizophrenia: Evidence for progressive deterioration. Schizophr Bull 18:437-448

Bilker WB, Carroll, RJ, Gur RC. A two-factor ANOVA-like test for correlated correlations: CORANOVA. Submitted

Blanchard JJ, Neale JM (1994): The neuropsychological signature of schizophrenia: Generalized or differential deficit? Am J Psychiat 151:40-48

Bleecker ML, Bolla-Wilson K, Agnew J, Meyers DA (1988): Age-related sex differences in verbal memory. J Clin Psychol 44:403-411

Buchanan RW, Holstein C, Breier A (1994): The comparative efficacy and long-term effects of clozapine treatment on neuropsychological test performance. Biol Psychiat 36: $717-725$

Calev A, Venables PH, Monk AF (1983): Evidence for distinct verbal memory pathologies in severely and mildly disturbed schizophrenics. Schizophr Bull 9:247-264

Censits DM, Ragland JD, Gur RC, Gur RE (1997): Neuropsychological evidence supporting a neurodevelopmental model of schizophrenia: A longitudinal study. Schizophr Res 24:289-298

Chute DL, Westall RF (1997): Power Laboratory. Devon PA, MacLaboratory Incorporated

Cronbach LJ, Meehl PE (1955): Construct validity in psychological tests. Psychol Bull 52:281-302

Daniel DG, Goldberg TE, Weinberger DR, Kleinman JE, Picar D, Lubick LJ, Williams TS (1996): Different side effects profiles of risperidone and clozapine in 20 outpatients with schizophrenia or schizoaffective disorder: A pilot study. Am J Psychiat 153:417-419

Delis DC, Kramer JH, Kaplan E, Ober BA (1983): California Verbal Learning Test (CVLT) manual. New York, The Psychological Corporation

Diggle PJ, Liang KY, Zeger SL (1994): Analysis of longitudinal data. New York, Oxford University Press

Glahn DC, Cannon TD, Gur RE, Ragland JD, Gur RC (2000): Working memory constrains abstraction in schizophrenia. Biol Psychiat 47:34-42

Glahn DC, Gur RC, Ragland JD, Gur RE (1997): Reliability, performance characteristics, and construct validity and initial application of the visual object learning test (VOLT). Neuropsychology 11:602-612

Gold JM, Caleb Q, Iannone VN, Buchanan RW (1999): Repeatable battery for the assessment of neuropsychological status as a screening test in schizophrenia. I: Sensitivity, reliability, and validity. Am J Psychiat 156: 1944-1950

Gold JM, Randolph C, Carpenter CJ, Goldberg TE, Weinberger DR (1992): Forms of memory failure in schizophrenia. J Abnorm Psychol 101:487-494

Goldberg TE, Weinberger DR, Berman KF, Pliskin NH, Podd MH (1987): Further evidence for dementia of the prefrontal type in schizophrenia? A controlled study of teaching the Wisconsin Card Sorting Test. Arch Gen Psychiat 44:1008-1014

Golden CJ, Purisch AD, Hammeke TA (1991): LuriaNebraska Neuropsychological Battery: Forms I and II. Los angeles, Western Psychological Services
Goldstein G (1986): The neuropsychology of schizophrenia. In Grant I, Adams KM (eds), Neuropsychological Assessment of Neuropsychiatric Disorders. New York, Oxford University Press

Goldstein JM, Seidman LJ, Goodman JM, Koren D, Lee H, Weintraub S, Tsuang MT (1998): Are there sex differences in neuropsychological functions among patients with schizophrenia? Am J Psychiat 155:1358-1364

Goodglass H, Kaplan E (1983): The Assessment of Aphasia and Related Disorders, 2nd ed. Philadelphia, Lea \& Febiger

Gordon M (1986): Manual, Gordon Diagnostic System. New York: Gordon Diagnostic Systems, Inc.

Green MF (1996): What are the functional consequences of neurocognitive deficits in schizophrenia? Am J Psychiat 154:321-330

Green MF, Marshall BD, Wirshing WC, Ames D, Marder SR, McGurk S, Kern RS, Mintz J (1997): Does Resperidone improve verbal working memory in treatment-resistant schizophrenia? Am J Psychiat 154:799-804

Gur RC, Jaggi JL, Ragland JD, Resnick SM, Shtasel D, Muenz L, Gur RE (1993): Effects of memory processing on regional brain activation: Cerebral blood flow in normal subjects. Int J Neurosci 72:31-44

Gur RC, Ragland JD, Gur RE (1997): Cognitive changes in schizophrenia: A critical look. Inter Rev Psychiat 9:449-457

Gur RC, Ragland JD, Moberg PJ, Turner TH, Bilker WB, Kohler C, Siegel SJ, Gur RE (2001): Computerized neurocognitive scanning: I. Methodology and validation in healthy people. Neuropsychopharmacology 25:766-776

Gur RC, Reivich M (1980): Cognitive task effects on hemispheric blood flow in humans: Evidence for individual differences in hemispheric activation. Brain Lang 9:78-92

Gur RC, Turetsky BI, Matsui M, Yan M, Bilker WB, Hughett P, Gur RE (1999a): Sex differences in brain gray and white matter in healthy young adults. J Neurosci 19:4065-4072

Gur RE, Cowell P, Turetsky BI, Gallacher F, Cannon T, Bilker WB, Gur RC (1998): A followup MRI study of schizophrenia: Relationship of neuroanatomic changes with clinical and neurobehavioral measures. Arch Gen Psychiat 55:145-152

Gur RE, Mozley D, Resnick SM, Levick S, Erwin R, Saykin AJ, Gur RC (1991): Relations among clinical scales in schizophrenia: Overlap and subtypes. Am J Psychiat 148:472-478

Gur RE, Petty RG, Turetsky BI, Gur RC (1996): Schizophrenia throughout life: Sex differences in severity and profile of symptoms. Schizophr Res 2:1-12

Gur RE, Turetsky BI, Bilker WB, Gur RC (1999b): Reduced gray matter volume in schizophrenia. Arch Gen Psychiat 56:905-911

Häfner H, Maurer K, Loffler W, Riecher-Rossler A (1993): The influence of age and sex on the onset and early course of schizophrenia. Br J Psychiat 162:80-86

Hagger C, Buckley P, Kenny JT, Friedman L, Ubogy D, Meltzer HY (1993): Improvement in cognitive functions and psychiatric symptoms in treatment-refractory schizophrenic patients receiving clozapine. Biol Psychiat 34:702-712 
Hanley JA, McNeil BJ (1982): The meaning and use of the area under a receiver operating characteristic (ROC) curve. Radiology 143:29-36

Harris JG Jr (1975): An abbreviated form of the Phillips Rating Scale of Premorbid Adjustment in schizophrenia. J Abnorm Psychol 84:129-137

Heaton RK (1981): Wisconsin Card Sorting Test Manual. Lutz, FL, Psychological Assessment Resources

Heaton RK, Paulsen JS, McAdams LA, Kuck J, Zisook S, Braff D, Harris MJ, Jeste DV (1994): Neuropsychological deficits in schizophrenics relationship to age, chronicity, and dementia. Arch Gen Psychiat 51:469-476

Henrichs DW, Hanlon TE, Carpenter WT (1984): The quality of life scale: An instrument for rating the schizophrenic deficit syndrome. Schizophr Bull 10:388-398

Hobart MP, Goldberg R, Bartko JJ, Gold JM (1999): Repeatable battery for the assessment of neuropsychological status as a screening test in schizophrenia. II: Convergent/discriminant validity and diagnostic group comparisons. Am J Psychiat 156:1951-1957

Hoff AL, Faustman WO, Wieneke M, Espinoza S, Costa M, Wolkowitz O, Csernansky JG (1996): The effects of clozapine on symptom reduction, neurocognitive function, and clinical management in treatment-refractory state hospital schizophrenic inpatients. Neuropsychopharmacology 15:361-369

Hoff AL, Riordan H, O'Donnell DW, DeLisi LE (1991): Cross-sectional and longitudinal neuropsychological test findings in first episode schizophrenic patients. Schiz Res 5:197-198

Kimura D, Harshman RA (1984): Sex differences in brain organization for verbal and nonverbal functions. Prog Brain Res 61:423-441

Kramer JH, Delis DC, Daniel M (1988): Sex differences in verbal learning. J Clin Psychol 44:907-915

Kurtz MM, Ragland JD, Bilker WB, Gur RC, Gur RE (2001): Comparison of two forms of the continuous performance test, with and without working memory demands in healthy controls and patients with schizophrenia. Schiz Res 48:307-316

Lewine RJ, Walker EF, Shurett R, Caudle J, Haden C (1996): Sex differences in neuropsychological functioning among schizophrenic patients. Am J Psychiat 153:1178-1184
McKenna PJ, Tamlyn D, Lund CE, Mortimer AM, Hammond S, Baddeley AD (1990): Amnesic syndrome in schizophrenia. Psych Med 20:967-972

Metz CE (1978): Basic principles of ROC analysis. Seminars Nucl Med 8:283-298

Olkin I, Finn J (1990): Testing correlated correlations. Psychol Bull 108:330-333

Peterson WW, Birdsall TG, Fox WC (1954): The theory of signal detection. Trans IRE Professional Group on Information Theory, PGIT 4:171-212

Ragland JD, Gur RE, Klimas BC, McGrady N, Gur RC (1999): Neuropsychological laterality indices of schizophrenia: Interactions with gender. Schizophr Bull 25:79-89

Ragland JD, Coleman AR, Gur RC, Glahn DC, Gur RE (2000): Sex differences in brain-behavior relationships between verbal episodic memory and resting regional cerebral blood flow. Neuropsychologia 38:451-461

Raven JC (1960): Guide to the standard progressive matrices. London, H.K. Lewis

Reitan RM, Woltson D (1985): The Halstead-Reitan Neuropsychological Test Battery, Theory, and Clinical Interpretation. Tucson, AZ: Neuropsychology Press

Saykin AJ, Gur RC, Gur RE, Mozley PD, Mozley LH, Resnick SM, Kester DB, Stafiniak P (1991): Neuropsychological function in schizophrenia: Selective impairment in memory and learning. Arch Gen Psychiat 48:618-624

Saykin AJ, Shtasel DL, Gur RE, Kester DB, Mozley LH, Stafiniak P, Gur RC (1994): Neuropsychological deficits in neuroleptic naive, first episode schizophrenic patients. Arch Gen Psychiat 51:124-131

Stroop JR (1935): Studies of interference in serial verbal reactions. J Exp Psychol 18:643-662

Wechsler DA (1981): Wechsler Adult Intelligence Scale Revised (WAIS-R) Manual. Cleveland, The Psychological Corp.

Wechsler DA (1987): Wechsler Memory Scale Revised (WMS-R). Cleveland, The Psychological Corp.

Zeger SL, Liang KY (1986): Longitudinal data analysis for discrete and continuous outcomes. Biometrics 42:121-130 